Boise State University

ScholarWorks

$5-2018$

Estimation of Porosity and Water Saturation in Dual-Porosity

Pyroclastic Deposits from Joint Analysis of Compression, Shear, and Electromagnetic Velocities

Andrew C. Gase

University of Texas at Austin

John H. Bradford

Colorado School of Mines

Brittany D. Brand

Boise State University 


\title{
Estimation of porosity and water saturation in dual-porosity pyroclastic deposits from joint analysis of compression, shear, and electromagnetic velocities
}

\author{
Andrew C. Gase ${ }^{1}$, John H. Bradford ${ }^{2}$, and Brittany D. Brand ${ }^{3}$
}

\begin{abstract}
In situ measurements of porosity and water saturation of pyroclastic deposits have the potential to improve interpretations of geology and hydrology in volcanic regions, and to provide more accurate estimates of dense rock equivalent for volcanic eruptions. However, rock-property models must consider the dual-porosity structure of pyroclastic deposits (i.e., vesicles within pumices and intergranular pores). Vesicularity, intergranular porosity, and water saturation all affect the density, elasticity, and dielectric properties of pyroclastic materials, which control seismic and electromagnetic velocities. The data from active seismic and ground-penetrating radar (GPR) techniques may improve porosity and water saturation estimation if the responses of seismic and electromagnetic velocities to porosity and water saturation variations are complementary in pyroclastic deposits. We developed a dual-porosity petrophysical model to calculate
\end{abstract}

seismic and electromagnetic velocities of pyroclastic deposits with known intergranular porosity, vesicularity, and water saturation, and we tested our ability to estimate porosity and water saturation from field measurements of seismic and electromagnetic velocities in pyroclastic deposits at Mount St. Helens, Washington, USA. Our petrophysical model demonstrates that seismic velocities are more sensitive to intergranular porosity and less sensitive to vesicularity; electromagnetic velocity is primarily controlled by volumetric water content. In a multioffset GPR and active seismic case study, seismic first-arrival traveltime tomography and multichannel analysis of surface waves can resolve high-velocity anomalies caused by porosity reduction. Joint petrophysical inversion of electromagnetic and seismic velocities indicates that although intergranular porosity and water saturation are well-constrained (i.e., standard deviations of approximately 0.05), quantitative estimates of vesicularity remain less certain (i.e., standard deviation of approximately 0.21 ), due to weak sensitivity.

\section{INTRODUCTION}

Ground-penetrating radar (GPR) and active seismic methods are among the most effective means of imaging the shallow subsurface. When paired with accurate rock-physics models, seismic and electromagnetic velocities can be used to estimate porosity and/or water content (e.g., Greaves et al., 1996; Bradford et al., 2009; Holbrook et al., 2014; Pasquet et al., 2016). However, deposits with a unique porosity structure can violate the assumptions of common sediment rock-physics models, complicating material property estimation.

Porosity within pyroclastic deposits derives from intergranular pores and vesicles within pumice grains (Figure 1), resulting in unique physical characteristics. Nur et al. (1998) note that pumices maintain high seismic velocities at porosities greater than most natural rocks (i.e., as much as 0.8 ). Pumices are often so porous that they float in water (Whitham and Sparks, 1986). In addition, the sedimentary characteristics of pyroclastic deposits such as grain size, sorting, welding (i.e., fusion of grains at high temperature), and grain angularity can vary significantly over relatively short distances. Yet, how the dual-porosity structure affects in situ seismic and electromagnetic velocities of pyroclastic deposits remains unexamined.

Many factors affect the porosity of pyroclastic deposits. The total porosity $\varphi$ relates to vesicularity $\varphi_{v}$ and intergranular porosity $\varphi_{g}$ as

$$
\varphi=\varphi_{v}\left(1-\varphi_{g}\right)+\varphi_{g}
$$

Manuscript received by the Editor 18 April 2017; revised manuscript received 19 October 2017; published ahead of production 10 January 2018; published online 23 February 2018.

${ }^{1}$ University of Texas at Austin, Jackson School of Geosciences, Institute for Geophysics, Austin, Texas, USA. E-mail: agase@utexas.edu.

${ }^{2}$ Colorado School of Mines, Department of Geophysics, Golden, Colorado, USA. E-mail: jbradford@mines.edu.

${ }^{3}$ Boise State University, Department of Geosciences, Boise, Idaho, USA. E-mail: brittanybrand@boisestate.edu.

(C) 2018 Society of Exploration Geophysicists. All rights reserved. 
Vesicles within pumices can vary in spatial distribution, size, and shape (Figure 1b; e.g., Klug and Cashman, 1994), which also affects the water content within individual pyroclasts (e.g., Whitham and Sparks, 1986; Manville et al., 1998; Fauria et al., 2017). Granulometric properties, such as sorting and grain shape, control intergranular porosity. For instance, poorly sorted sediments are less porous than are well-sorted sediments (e.g., Rogers and Head, 1961). Mixed lithologies with grain size and sorting distributions comparable to pyroclastic deposits, such as alluvial sediments, exhibit intergranular porosities between approximately 0.1 and 0.5 (e.g., Barrash and Clemo, 2002).

In situ rock-property estimation has the potential to improve the interpretation of geologic and hydrologic processes in volcanic terrains. Total porosity measurements are particularly useful for obtaining dense rock equivalent estimates of volcanic eruptions. Notable geophysical studies in pyroclastic deposits include 1D electromagnetic velocity $V_{\mathrm{EM}}$ measurements with GPR (Rust and Russell, 2001) and P-wave velocity $V_{\mathrm{P}}$ traveltime tomography (Bais et al., 2003). However, existing studies lack overlapping electromagnetic and seismic measurements, and rock-physics models that can account for water content and dual porosity in unsaturated conditions.

The objectives of this study are to

1) simulate the effects of dual porosity and water content on seismic and electromagnetic velocities and

2) estimate porosity and water saturation of pyroclastic deposits with seismic and electromagnetic velocities.

We develop a joint electromagnetic and seismic petrophysical model for pyroclastic deposits and conduct coincident multioffset GPR and active seismic surveys in pyroclastic deposits at Mount St. Helens (MSH), Washington, USA.

\section{Petrophysical Background}

Assuming the magnetic permeability of free space and negligible electrical conductivity, electromagnetic velocity $V_{\mathrm{EM}}$ is

$$
V_{\mathrm{EM}}=\frac{c}{\sqrt{\varepsilon}},
$$

a)

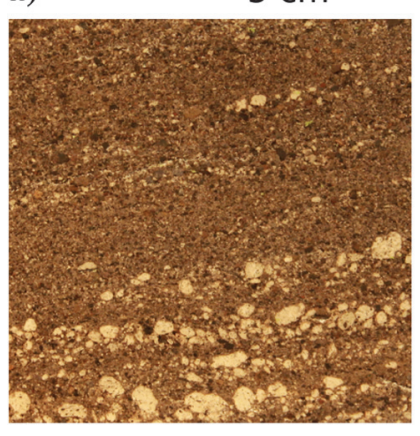

b)

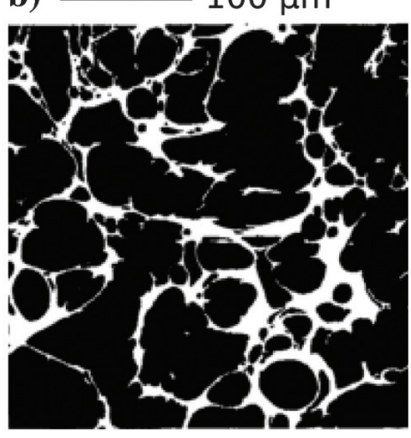

Figure 1. (a) Photograph of epoxied pyroclastic deposits from MSH. The grains are a mixture of white pumice and nonjuvenile lithics that range in size from ash $(<2 \mathrm{~mm})$ to fine lapilli (approximately $1 \mathrm{~cm}$ ). (b) Binary scanning electron microscope image of a MSH pumice thin-section illustrates the high proportion of vesicles (black) relative to the vesicle walls (white) (modified from Klug and Cashman, 1994). where $c$ is the speed of light in a vacuum and $\varepsilon$ is the relative permittivity. Air-filled pores reduce $\varepsilon$ and thereby increase $V_{\mathrm{EM}}$. Rust et al. (1999) determine empirical equations to estimate $V_{\mathrm{EM}}$ of dry volcanic rocks with known $\varphi$ and composition. Yet, water in partially saturated deposits can significantly reduce $V_{\mathrm{EM}}$. This effect prevents the use of these solid-air empirical equations due to the high relative permittivity of water $\left(\varepsilon_{w}=80\right)$ with respect to the relative permittivity of volcanic rocks, such as dacite $\left(\varepsilon_{d}=6.79\right)$ (Rust et al., 1999; Rust and Russell, 2001). Therefore, attempts to calculate $\varphi$ from $V_{\mathrm{EM}}$ that ignore present water will underestimate $\varphi$. Although porosity has a theoretical effect on $V_{\mathrm{EM}}$ (Rust and Russell, 2000), $V_{\mathrm{EM}}$ and GPR reflections are primarily controlled by water content (Topp et al., 1980; Van Dam and Schlager, 2000).

GPR can be applied to estimate water content in soils with the equation of Topp et al. (1980) (e.g., Greaves et al., 1996; Huisman et al., 2003; Bradford, 2008). Alternatively, Bradford et al. (2009) estimate $\varphi$ for water-saturated alluvial sediments with the complex refractive index method (CRIM) (Wharton et al., 1980). However, an earth model with pore spaces occupied by water and air cannot be resolved with GPR alone because $V_{\mathrm{EM}}$ depends on water saturation $S_{w}$ and $\varphi$ (Figure 2a, 2d, and $2 \mathrm{~g}$ ). In addition, assuming $\varphi_{v}$ and $\varphi_{g}$ are sufficiently independent, three separate geophysical parameters are required to constrain dual porosity in partially saturated pyroclastic deposits.

At depths $<10 \mathrm{~m}$ and for the source frequencies used in this study, active seismic methods and GPR have comparable resolution. First-arrival traveltime tomography and Rayleigh-wave inversion are common techniques for estimating $V_{\mathrm{P}}$ and $V_{\mathrm{S}}$, respectively. The terms $V_{\mathrm{P}}$ and $V_{\mathrm{S}}$ are

$$
V_{\mathrm{P}}=\sqrt{\frac{\mathrm{K}+\frac{4}{3} G}{\rho}},
$$

$$
V_{\mathrm{S}}=\sqrt{\frac{\mathrm{G}}{\rho}},
$$

where $K$ is the bulk modulus, $G$ is the shear modulus, and $\rho$ is the density. In unconsolidated and unsaturated sediments $\left(S_{w}<0.99\right), V_{\mathrm{P}}$ and $V_{\mathrm{S}}$ are primarily sensitive to stiffness of the sediment matrix, grain size, degree of compaction, and $\rho$, and they are secondarily sensitive to the capillary and pore pressure effects of water along grain contacts (see Santamarina et al., 2005). Thus, $V_{\mathrm{P}}$ and $V_{\mathrm{S}}$ are more sensitive to $\varphi$ than to $S_{w}$ at partial saturation (Figure 2b, 2c, 2e, and $2 \mathrm{f}$ ).

We model pyroclastic deposits as a partially saturated, unconsolidated sediment with constant grain size and random packing, composed of vesicular dacite grains. We use the composition of pyroclastic density current deposits from 18 May 1980 eruption, which includes pyroxene, hornblende, plagioclase feldspar, and volcanic glass (Table 1) (mineral proportions from Kuntz et al., 1981; isotropic elastic constants are from Bass, 1995; Mavko et al., 2009). We assume that $S_{w}$ is equal between vesicles and intergranular pores. This assumption has a negligible effect on modeled seismic velocities at partial saturation because the water content primarily affects density, rather than the bulk modulus. We perform the 
following steps to model electromagnetic and seismic velocities (equations detailed in Appendix A):

1) Compute relative permittivity of vesicular dacite nested within a sediment matrix using the CRIM equation (Wharton et al., 1980). Electromagnetic velocities follow with equation 2.

2) Calculate the bulk and shear moduli for pumice grains of known mineralogy, $\varphi_{v}$, and $S_{\mathrm{w}}$ with the critical porosity equation of Nur et al. (1998) and Gassmann's equations (Gassmann, 1951).

3 ) Using the computed pumice grain elastic properties, calculate the dry bulk modulus $\left(K_{\text {dry }}\right)$ and shear modulus $\left(G_{\text {dry }}\right)$ of a pumice sediment with known $\varphi_{g}$ and effective stress with the Hertz-Mindlin contact theory (Mindlin, 1949) and the modified Hashin-Shtrikman bounds of Helgerud et al. (1999).

4) Calculate the bulk and shear moduli of the sediment at partial saturation with $S_{w}$ as in Santamarina et al. (2005). Seismic velocities follow with equations 3 and 4 .

Using this petrophysical model, we examine the sensitivities of electromagnetic and seismic velocities to $S_{w}, \varphi_{g}$, and $\varphi_{v}$ ranging from 0 to 0.8 (Figure 2). We display the 3D parameter space in slices at $\varphi_{v}$ of 0.7 (Figure 2a-2c), $\varphi_{g}$ of 0.3 (Figure $2 \mathrm{~d}-2 \mathrm{f}$ ), and $S_{w}$ of 0.25 (Figure $2 \mathrm{~g}-2 \mathrm{i}$ ). The model confirms the strong sensitivity of $V_{\mathrm{EM}}$ to the volumetric water content (i.e., the product of water saturation and total porosity; Figure $2 \mathrm{a}, 2 \mathrm{~d}$, and $2 \mathrm{~g}$ ). Intergranular porosity strongly affects seismic velocities (Figure $2 b, 2 c, 2 h$, and $2 \mathrm{i}$ ), whereas the effects of vesicularity and water saturation on seismic velocities are notably less significant (Figure $2 \mathrm{~h}$ and $2 \mathrm{i}$ ). The independent sensitivities of electromagnetic and seismic velocities demonstrate that overlapping GPR and seismic measurements may uniquely constrain $S_{w}$ and $\varphi$ in deposits with a single porosity distribution. However, it is unclear whether $\varphi_{g}$ and $\varphi_{v}$ are sufficiently independent for unique determination.

Table 1. Densities $\rho_{i}$, bulk moduli $K_{i}$, shear moduli $G_{i}$ and volumetric proportions of mineral phases within dacite from 18 May 1980 pyroclastic density current deposits of MSH.

\begin{tabular}{lcccc} 
Mineral phase & $\begin{array}{c}\rho_{i} \\
\left(\mathrm{~kg} \mathrm{~m}^{-3}\right)\end{array}$ & $\begin{array}{c}K_{i} \\
(\mathrm{GPa})\end{array}$ & $\begin{array}{c}G_{i} \\
(\mathrm{GPa})\end{array}$ & $\begin{array}{c}\text { Volume } \\
\text { fraction }(\%)\end{array}$ \\
\hline Volcanic glass (obsidian) & 2331 & 37.8 & 30.1 & 62.1 \\
Orthopyroxene & 3310 & 111.2 & 63.7 & 4.2 \\
Hornblende & 3120 & 87 & 43 & 2.5 \\
Plagioclase-feldspar & 2630 & 75.6 & 25.6 & 30.0 \\
Fe-Ti oxide & 5009 & 161.1 & 91.4 & 1.2 \\
\hline
\end{tabular}
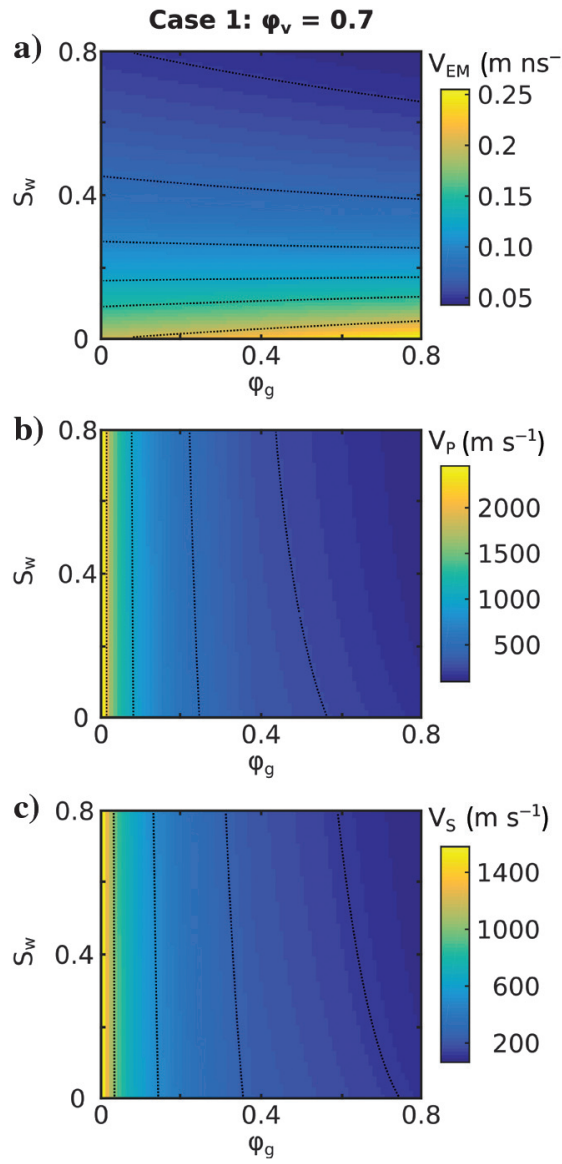
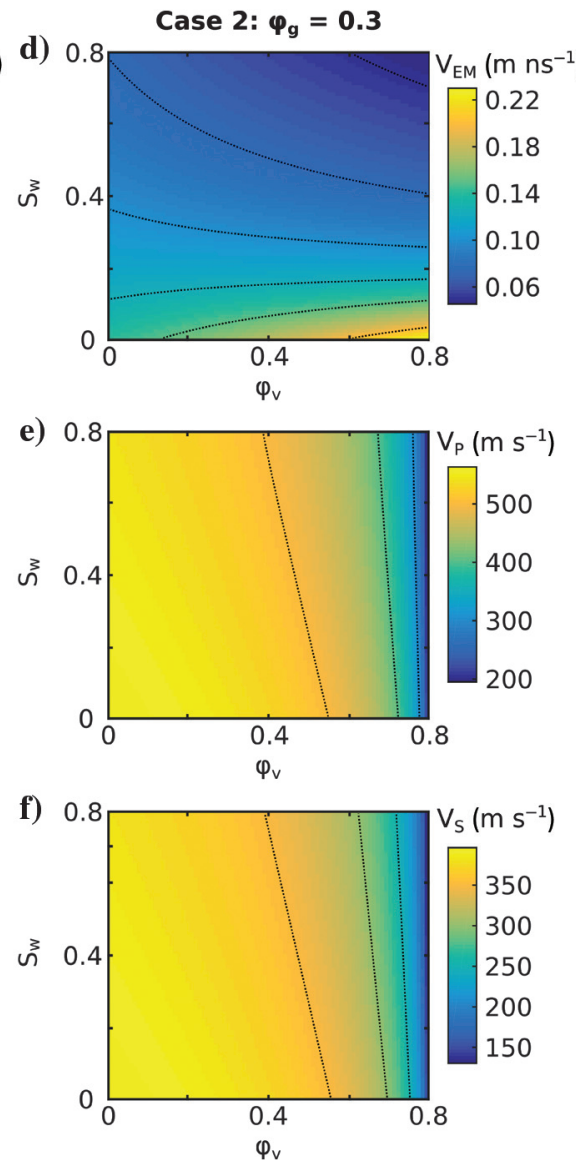
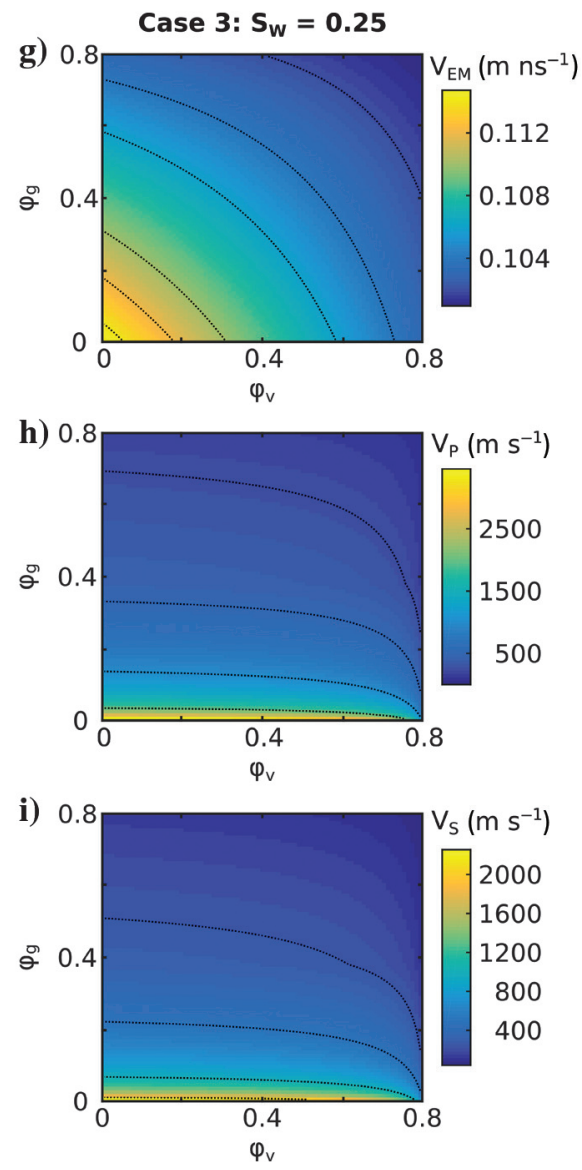

Figure 2. Simulated electromagnetic (first row), P-wave (second row), and S-wave (third row) velocities for pyroclastic deposits at a $5 \mathrm{~m}$ depth, for $S_{w}, \varphi_{g}$, and $\varphi_{v}$ ranging from 0 to 0.80 . Columns represent slices of the 3D parameter space at constant values of $\varphi_{v}, \varphi_{g}$, and $S_{w}$, respectively. 


\section{CASE STUDY: MSH}

\section{Survey setting}

In July 2015, we acquired a line of GPR and active seismic data at MSH, approximately $5 \mathrm{~km}$ north of the crater (Figure 3a). A $30 \mathrm{~m}$ thick outcrop described by Brand et al. (2014) is adjacent to the line (Figure 3b). Single-offset GPR imaging by Gase et al. (2017) shows that the stratigraphy in the outcrop extends beneath the line. The underlying sequence contains four chronological flow units deposited by column-collapse pyroclastic density currents from the 18 May 1980 eruption (Figure 3c). Unit I is uniform, massive, and capped by approximately $50 \mathrm{~cm}$ thick layer of ash. Unit II is dif- fusely stratified and thickest at the southern end of the outcrop. The Unit II-III boundary is sharp and unconformable; the pyroclastic density current responsible for Unit III scoured a channel approximately $8 \mathrm{~m}$ into Unit II before becoming depositional (Brand et al., 2014). Unit III fills the scour with a massive lapilli tuff and a lithic breccia with meter-scale boulders. The transition between Units III and IV is typically gradational, although at the center of the outcrop, Unit IV caps Unit III with a lithic breccia lens and grades into a massive lapilli tuff. The juvenile material is dacite tephra, and accidental blocks within pyroclastic deposits are composed of basaltic-andesite, andesite, dacite, and rhyodacite (Kuntz et al., 1981). We assume that the water table mimics the north-descending gradient of the adjacent stream, approximately $30 \mathrm{~m}$ beneath the surface.

\section{GPR acquisition and processing}

We collected $234 \mathrm{~m}$ of multioffset GPR data according to the acquisition parameters in Table 2. A GPR streamer was pulled across the ground surface for four passes (Figure 4). Each pass accounted for eight offsets, which we increased successively. We binned source and receiver locations to common midpoints (CMPs) according to real-time kinematic GPS measurements.

Maximum reflection traveltimes range between 200 and 400 ns (Figure 5a). Initial GPR processing included time-zero correction, band-pass frequency filtering (12-25-200-300 MHz), and automatic gain control (30 ns time gate). Eigenvector filtering removed laterally continuous background noise at the bottom of the time window. The data were corrected for normal moveout (NMO), stacked, and frequency-wavenumber ( $f-k)$ migrated at $0.092 \mathrm{~m} \mathrm{~ns}^{-1}$ (Figure 5b).

Bradford (2006) demonstrates that prestackdepth migration (PSDM) and reflection tomography of multifold GPR radar data can significantly improve the signal-to-noise and provide more

Table 2. Parameters for GPR and seismic acquisition.

GPR acquisition parameters

Seismic acquisition parameters

\begin{tabular}{|c|c|c|c|}
\hline GPR system & $\begin{array}{l}\text { Sensors and Software PE Pro, } 100 \mathrm{MHz} \text { unshielded } \\
\text { antennas, two } 400 \mathrm{~V} \text { transmitters, four receivers }\end{array}$ & Seismograph & $\begin{array}{l}\text { Geometrics, Geode, } 24 \text { channel; } \\
10 \mathrm{~Hz} \text { vertical geophones }\end{array}$ \\
\hline Geometry & $\begin{array}{l}\text { Transverse electric, } 2 \mathrm{D} \text {, acquired in two passes in } \\
\text { both directions with eight transmitter/receiver pairs }\end{array}$ & Geometry & Inline \\
\hline CMP fold & 16 (double 8 and $8.5 \mathrm{~m}$ offset) & Source & $3.6 \mathrm{~kg}$ sledgehammer \\
\hline $\begin{array}{l}\text { Minimum/maximum } \\
\text { offset }(\mathrm{m}) \text { per pass }\end{array}$ & $-1 / 8,1.5 / 8.5,-8 / 15,8.5 / 15.5$ & $\begin{array}{l}\text { Minimum/maximum } \\
\text { offset (m) }\end{array}$ & $0 / 142$ \\
\hline CMP bin size $(\mathrm{m})$ & 0.29 & Number of channels & 72 \\
\hline Receiver interval (m) & 1 & Receiver interval (m) & 2 \\
\hline Source interval $(\mathrm{m})$ & 0.16 & Source interval (m) & 2 \\
\hline Sample interval (ns) & 0.8 & Sample interval (ms) & 0.5 \\
\hline Recording time (ns) & 400 & Recording time (ms) & 500 \\
\hline Stacks/source & 8 & Stacks/source & 4 \\
\hline
\end{tabular}


accurate velocity models than traditional GPR velocity estimation techniques. Using SeisSpace seismic data processing software, we performed Kirchhoff PSDM with an initial velocity of $0.092 \mathrm{mns}^{-1}$, followed by $2 \mathrm{D}$ reflection tomography in the postmigration domain to invert for a velocity model that minimized residual moveout of selected horizons (Figure 5c). We repeated PSDM with the inverted $2 \mathrm{D}$ velocity model. The migration results were sorted to commonimage point gathers, top muted to remove the stretched signal from PSDM, and stacked (Figure 5d).

\section{Seismic acquisition and processing}

We chose seismic acquisition parameters to record first arrivals for P-wave traveltime tomography and Rayleigh waves for multichannel analysis of surface waves (MASWs) at a resolution and depth comparable with the GPR data (Table 2). We recorded 168 shots along the $324 \mathrm{~m}$ seismic line. After 24 shots, the first 24 geophones were rolled to the end of the seismic line. We repeated this procedure until the 24 final stations were placed, after which we shot through to the final receiver station.

The shot gathers are of excellent quality (Figure 6a). Given the remote location and decent geophone coupling, noise is largely limited to movement of the survey team and the fan of the field computer. First-arrival velocities begin at lower than air velocity $\left(<350 \mathrm{~m} \mathrm{~s}^{-1}\right)$ and then increase slightly at near offsets $(<24 \mathrm{~m})$. A more abrupt increase in first-arrival velocity from approximately 400 to $1500 \mathrm{~m} \mathrm{~s}^{-1}$ at intermediate offsets is likely caused by the water-table refraction. Ground roll is strong across the spread and separates into distinct modes after the first 12 receiver stations. A water-table reflection overlaps with ground roll within the noise cone. Several deep reflections are present in the reflection envelope between the ground-roll and water-table refraction.

We band-pass frequency filtered (12-25-100$200 \mathrm{~Hz}$ ) the seismic data and picked first arrivals for each shot (12,096 picks total). Special attention was required to pick first arrivals at near offsets, which were often slower than the airwave (Figure 6a). Using Rayfract first-arrival traveltime tomography software, we modify a 1D initial $V_{\mathrm{P}}$ model with wavepath eikonal traveltime inversion for 150 iterations, resulting in the final 2D $V_{\mathrm{P}}$ model (Figure 7b).

We performed MASW by modifying the approach of Gribler et al. (2016), which requires Rayleigh waves across off-end shot gathers. Offsets nearer than approximately $20 \mathrm{~m}$ often contain high-amplitude body waves that degrade the dispersion curve clarity. Shot gathers were windowed to 24 channels equidistant from the shot station and the maximum positive offset on the shot gather (Figure 6b). We used only positive offsets to ensure a uniform distribution of midpoints. A top mute was applied to limit additional contamination by body waves and noise.

We generated dispersion curves from unfiltered shot gathers and picked fundamental modes between approximately 10 and $60 \mathrm{~Hz}$, only where

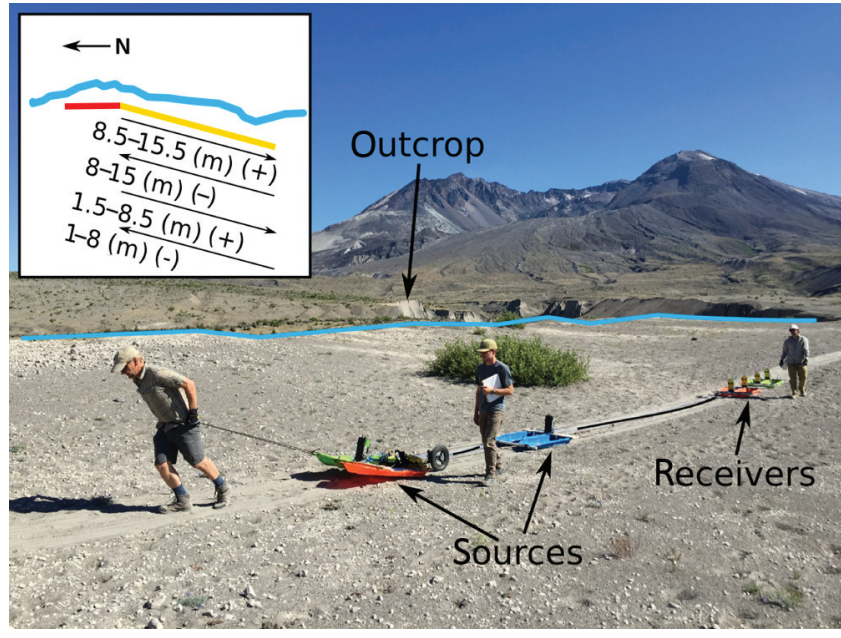

Figure 4. Photograph of multifold GPR acquisition with two sources and four receivers. Complete acquisition required four passes with expanded offsets (inset). The offset polarity is determined by whether the sources are north (negative) or south (positive) of the receiver.

a)
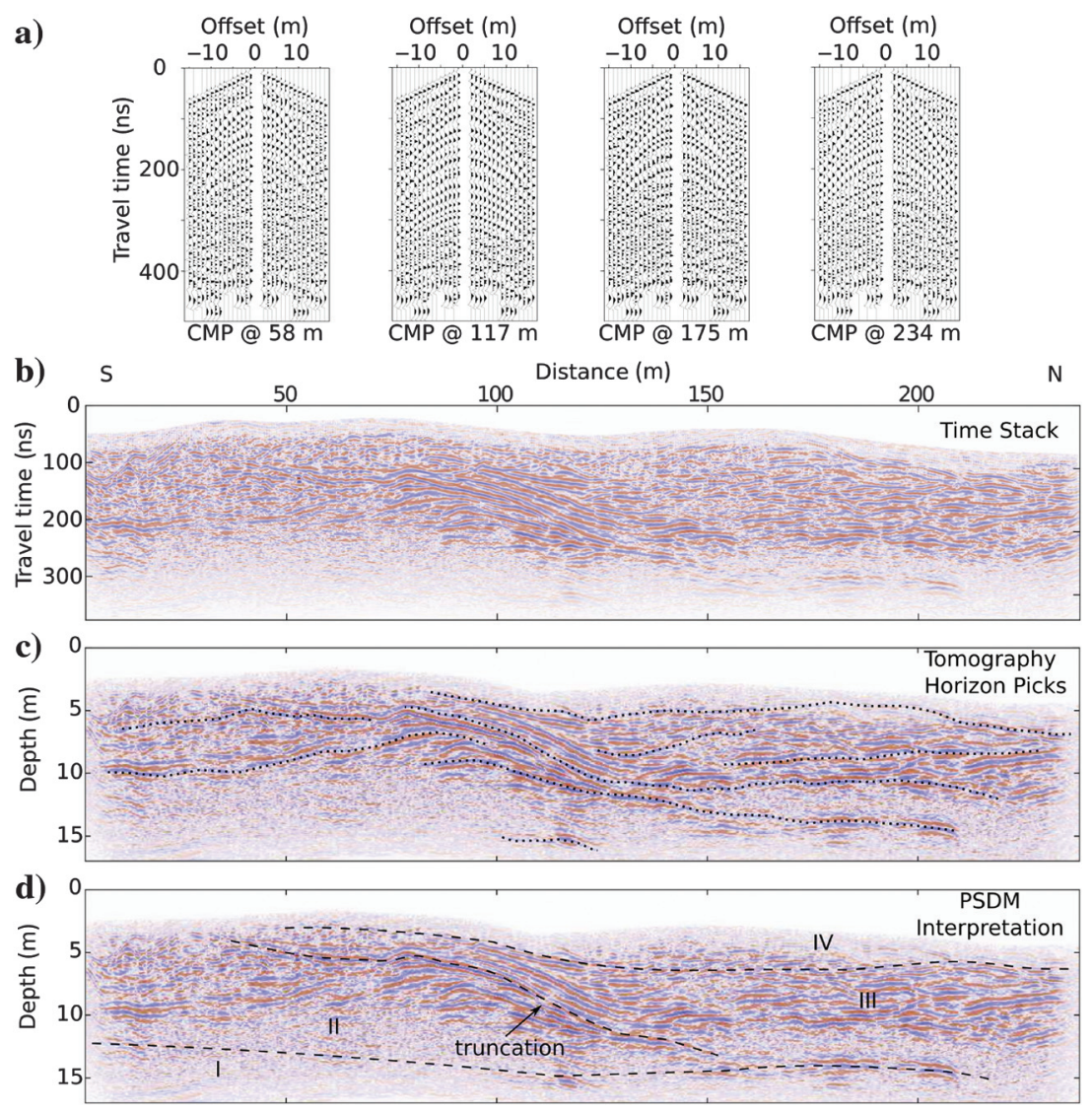

Figure 5. GPR reflectivity used to estimate the subsurface $V_{\mathrm{EM}}$ and correlate tomography results with underlying stratigraphy. (a) Representative CMP gathers show hyperbolic reflections. (b) Time stack after NMO correction, $f-k$ migration, and depth conversion at $0.092 \mathrm{~m} \mathrm{~ns}^{-1}$. (c) PSDM radargram with horizons selected for reflection tomography. (d) PSDM radargram with flow unit interpretations matching Figure 3c. 

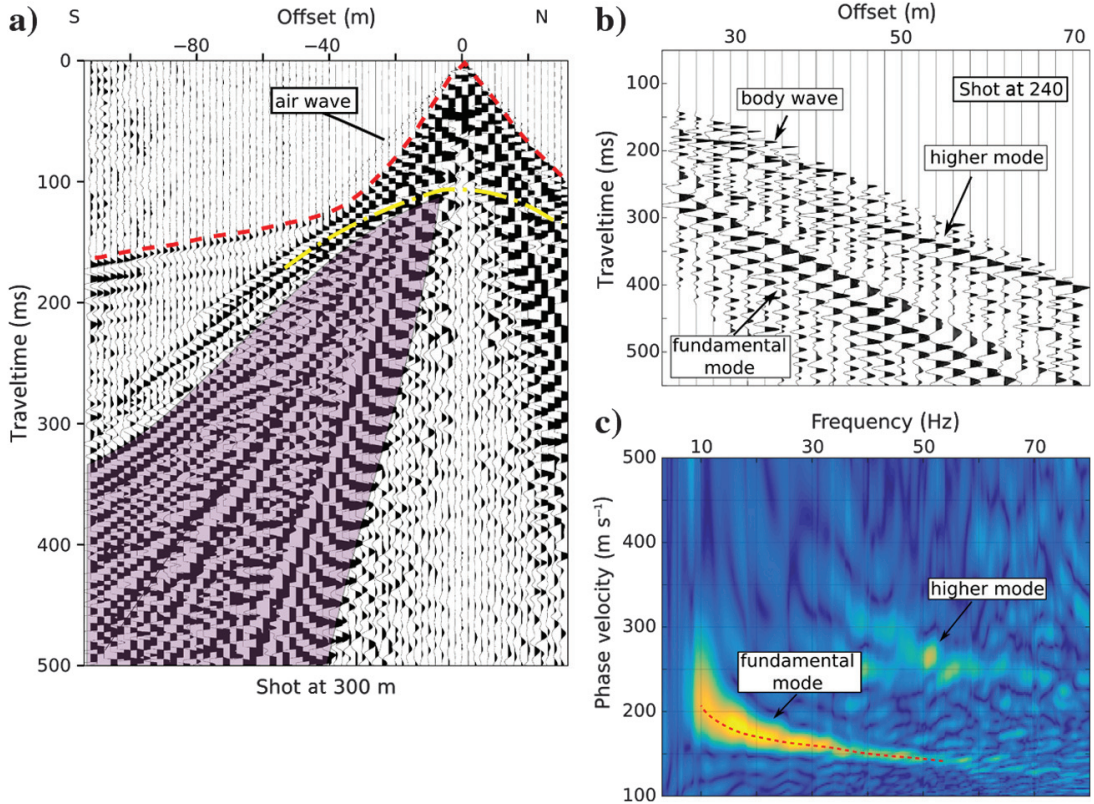

Figure 6. (a) A representative seismic shot gather shows first arrivals (red line) and significant ground roll (purple). Shot gathers have clear water-table refractions (first arrivals beyond approximately $40 \mathrm{~m}$ offset) and water-table reflections (yellow dashes). (b) Rayleigh waves are isolated for MASW. For example, shot 122 is windowed to offsets 12-78 $\mathrm{m}$. Data are muted before the ground roll to limit body-wave noise. (c) A dispersion curve depicts Rayleigh-wave frequency versus phase velocity of shot 122 . Dispersion curve picks are colored red.
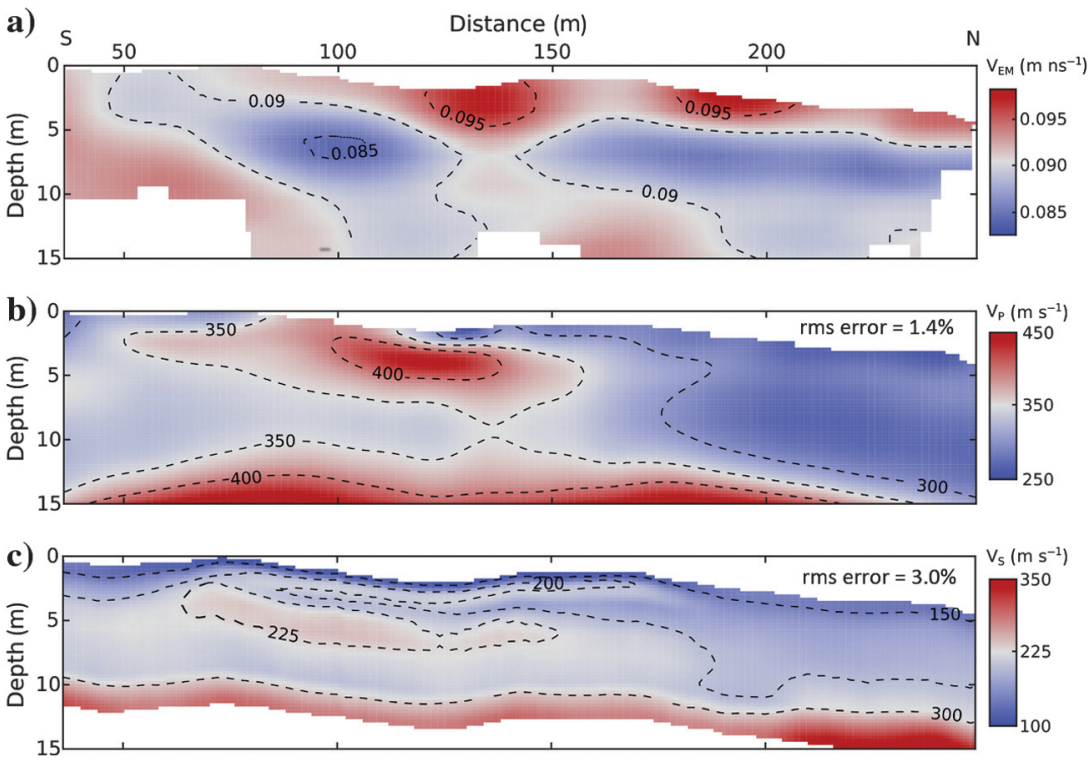

Figure 7. (a) EM-wave velocity model from reflection tomography of GPR data. Two broad low $V_{\mathrm{EM}}$ anomalies are centered at the horizontal positions 100 and $200 \mathrm{~m}$. (b) Pwave velocity model from inversion of first-arrival traveltimes. A high- $V_{\mathrm{P}}\left(>350 \mathrm{~m} \mathrm{~s}^{-1}\right)$ anomaly at approximately $4 \mathrm{~m}$ depth and horizontal position approximately $100 \mathrm{~m}$ is centered over the upper unit IV breccia lens (Figure 4). (c) S-wave model from inversion of the Rayleigh-wave dispersion curves. A high- $V_{\mathrm{S}}\left(>225 \mathrm{~m} \mathrm{~s}^{-1}\right)$ anomaly at approximately $5 \mathrm{~m}$ depth overlaps the high- $V_{\mathrm{P}}$ zone (b) and the upper unit IV breccia lens (Figure 3c). semblance is coherent (Figure 6c). The weak dispersion curve semblance at less than $10 \mathrm{~Hz}$ is likely due to the inability of the hammer source to generate lower frequencies, limiting depths achieved by MASW to approximately $10 \mathrm{~m}$. The $500 \mathrm{~ms}$ recording time and receiver window clip the fundamental modes at offsets $>30 \mathrm{~m}$, which we expect to degrade the dispersion curve coherence at high frequencies. This may result in significant uncertainty in $V_{\mathrm{S}}$ models in the upper 1-2 $\mathrm{m}$. We inverted dispersion curves for $1 \mathrm{D} V_{\mathrm{S}}$ models using SurfSeis2 Rayleigh-wave inversion software. We bin each inverted 1D $V_{\mathrm{S}}$ model at the midpoint of the off-end shot gather and horizontally smooth four midpoints to produce a pseudo-2D $V_{\mathrm{S}}$ model.

\section{Electromagnetic and seismic velocities}

Due to the differences in velocity estimation procedures, including inversion type, sensitivity, regularization, and grid sizes, no velocity result has the same resolution or uncertainty. In addition, the remote survey location lack the wells needed to quantify the measurement error. Our MASW and traveltime tomography inversion results have root-mean squared (rms) errors of $3 \%$ and $1.2 \%$, respectively. The GPR reflection tomography inversion evaluates error through qualitative improvement of the reflection image. Bradford et al. (2009) demonstrate that similar GPR acquisition and reflection tomography is capable of measurement errors of approximately $2 \%$.

Resolution of each velocity result depends on a combination of the wavelength, acquisition geometry, and the inversion procedure. The inversion programs used in this study do not provide comparable and robust uncertainty or resolution estimates. Assuming that the minimum size of resolvable features is at least half the wavelength, $100 \mathrm{MHz}$ electromagnetic wavelengths at velocities $\left(0.08-0.1 \mathrm{~m} \mathrm{~ns}^{-1}\right)$, can resolve approximately $0.4-1 \mathrm{~m}$ features. P-waves at approximately $50 \mathrm{~Hz}$ and velocities between approximately 200 and $500 \mathrm{~m} \mathrm{~s}^{-1}$ can resolve approximately 4-10 m features. Finally, we inverted Rayleigh waves with frequencies ranging from approximately 10 to $60 \mathrm{~Hz}$ with phase velocities between approximately 150 and $250 \mathrm{~m} \mathrm{~s}^{-1}$ (Figure 6c). Thus, the vertical resolution of $V_{\mathrm{S}}$ decreases from approximately 1.25 to $12.5 \mathrm{~m}$ with depth. Geometric controls on resolution include the receiver and shot intervals and raypaths. Short station intervals (i.e., $2 \mathrm{~m}$ for seismic, $0.58 \mathrm{~m}$ for GPR CMP) and dense coverage from near-vertical rays provide approximate lateral resolutions of $V_{\mathrm{EM}}$ and $V_{\mathrm{P}}$ approximately 1-2 m. However for MASW, which solves for 1D $V_{\mathrm{S}}$ soundings, horizontal smoothing across 
$66 \mathrm{~m}$ to produce pseudo-2D $V_{\mathrm{S}}$ profiles severely diminishes $V_{\mathrm{S}}$ lateral resolution. Despite resolution differences, we maintain that all three techniques have sufficiently compatible resolution for this study and are capable of detecting anomalies near the scale of the breccias in the adjacent outcrop (i.e., approximately $3 \mathrm{~m}$ thick, approximately $100 \mathrm{~m}$ long; Figure 3c).

Each velocity inversion technique applied in this study produces velocity models gridded with different horizontal and vertical spacing. The GPR velocity model is horizontally gridded at the CMP bin interval $(0.58 \mathrm{~m})$, whereas seismic velocity models are horizontally gridded at the station spacing (approximately $2 \mathrm{~m}$ ). We linearly interpolate velocity models to a $0.25 \mathrm{~m}$ horizontal and vertical interval grid to improve comparison between techniques.

In the final velocity model from the PSDM, electromagnetic velocities range from 0.083 to $0.1 \mathrm{~m} \mathrm{~ns}^{-1}$ with an average $V_{\mathrm{EM}}$ of $0.092 \mathrm{~m} \mathrm{~ns}^{-1}$ (Figure 7a). Electromagnetic velocities are greatest at the ground surface on the northern half of the line. Two areas of reduced $V_{\mathrm{EM}}\left(<0.09 \mathrm{mns}^{-1}\right)$ spread across the depth range and are split horizontally by higher velocity $\left(>0.095 \mathrm{~m} \mathrm{~ns}^{-1}\right)$ zone midline. P-wave velocity in the upper $15 \mathrm{~m}$ ranges from approximately 250 to $450 \mathrm{~m} \mathrm{~s}^{-1}$, increasing gradually with depth (Figure $7 \mathrm{~b}$ ). A lenticular anomaly of elevated $V_{\mathrm{P}}\left(>350 \mathrm{~m} \mathrm{~s}^{-1}\right)$ extends from horizontal positions $50-150 \mathrm{~m}$ at depths less than $7 \mathrm{~m}$. P-wave velocity beneath this anomaly is reduced but eventually increases at approximately $10 \mathrm{~m}$ depth. The P-wave velocity is lowest $\left(<300 \mathrm{~m} \mathrm{~s}^{-1}\right)$ on the northern third of the line in the upper $10 \mathrm{~m}$. The $\mathrm{S}$-wave velocity is low $\left(<150 \mathrm{~m} \mathrm{~s}^{-1}\right)$ in the upper meter and increases gradually with depth (Figure 7c). A similarly shaped anomaly of elevated $\left(>225 \mathrm{~ms}^{-1}\right) V_{\mathrm{S}}$ is present between 50 and $150 \mathrm{~m}$ at depths between 3 and $7 \mathrm{~m}$. As with $V_{\mathrm{P}}, V_{\mathrm{S}}$ is lower beneath the anomaly and again increases at approximately $10 \mathrm{~m}$ depth. The $\mathrm{S}$-wave velocity is also reduced $\left(<200 \mathrm{~m} \mathrm{~s}^{-1}\right)$ on the northern third of the line.

The three velocity models contain broad trends in velocity that relate to the interaction of the respective waves with subsurface properties. Electromagnetic velocity is primarily influenced by water content, even in unsaturated conditions, and thus it is distinct from $V_{\mathrm{P}}$ and $V_{\mathrm{S}}$. Electromagnetic velocity can vary greatly for unconsolidated sediments (approximately $0.2-0.05 \mathrm{~m} \mathrm{~ns}^{-1}$ ) depending on the volumetric water content. Our results fall within the reasonable range $\left(0.08-0.1 \mathrm{~m} \mathrm{~ns}^{-1}\right)$ for partial-saturation conditions with $\varepsilon$ ranging from 9 to 14 . The electromagnetic velocity is greatest in the very near surface where the deposits are the driest.
Low $V_{\mathrm{EM}}$ areas underlain by zones of higher $V_{\mathrm{EM}}$ suggest variations in deposit water content. A day of heavy rain preceded the survey, and the weather was hot (approximately $35^{\circ} \mathrm{C}$ ) and sunny during acquisition. Elevated $V_{\mathrm{EM}}$ at depths $<5 \mathrm{~m}$ may reflect a combination of drying in the near surface, vertical flow, or greater porosity in the upper $5 \mathrm{~m}$.

The P- and S-wave velocity models (Figure $7 \mathrm{~b}$ and $7 \mathrm{c}$ ) contain several similarities including increasing velocity with depth, a midline anomaly of elevated velocity, and reduced velocity along the northern third of the line. The midline anomaly of elevated velocity corresponds to the size and location of the upper lithic breccia shown in the outcrop (Figure 3c), which suggests that the boulders impart greater bulk rigidity on the deposit. This also explains the lower velocities of the northern third of the line where no breccias are present in the outcrop (Figure 3c). Lower vesicularity within the boulders is expected to increase the bulk and shear moduli of the breccias and contribute to elevated seismic velocities. Alternatively, poor sorting (typical of pyroclastic density current deposits) will reduce intergranular porosity (Rogers and Head, 1961) and increase seismic velocities (Zimmer et al., 2007). Thus, our results show evidence of reduced porosity where the $V_{\mathrm{P}}$ and $V_{\mathrm{S}}$ are elevated near poorly sorted breccia lenses.

In the upper $10 \mathrm{~m}$, seismic velocities (approximately $200-550 \mathrm{~m} \mathrm{~s}^{-1}$ for $V_{\mathrm{P}}$; approximately $100-500 \mathrm{~m} \mathrm{~s}^{-1}$ for $\left.V_{\mathrm{S}}\right)$ for pyroclastic deposits fall within the typical values $\left(<100-800 \mathrm{~m} \mathrm{~s}^{-1}\right.$ for $V_{\mathrm{P}} ;<100-500 \mathrm{~m} \mathrm{~s}^{-1}$ for $\left.V_{\mathrm{S}}\right)$ for near surface, partially saturated soils (Santamarina et al., 2005) and sands (Bachrach et al., 2000). However, the range of $V_{\mathrm{P}}$ we measure in the unconsolidated pyroclastic deposits is approximately half the $V_{\mathrm{P}}$ of the loose to partially welded pyroclastic deposits of the Neapolitan Yellow Tuff (Italy) (Bais et al., 2003), and approximately 20\%-30\% of $V_{\mathrm{P}}$ for tuff (Wohletz and Heiken, 1992).

\section{Petrophysical inversion}

Our ultimate goal is to transform geophysical parameters into rock properties via petrophysical inversion. Statistical seismic inversion schemes are often used for reservoir characterization in the oil industry, especially when coincident well data are available to measure uncertainty and constrain inversions (e.g., Bosch et al., 2010). However, exploratory studies that lack wells can resort to simpler and less robust schemes to estimate rock properties from inverted velocities (e.g., Holbrook et al., 2014; Pasquet et al., 2016).
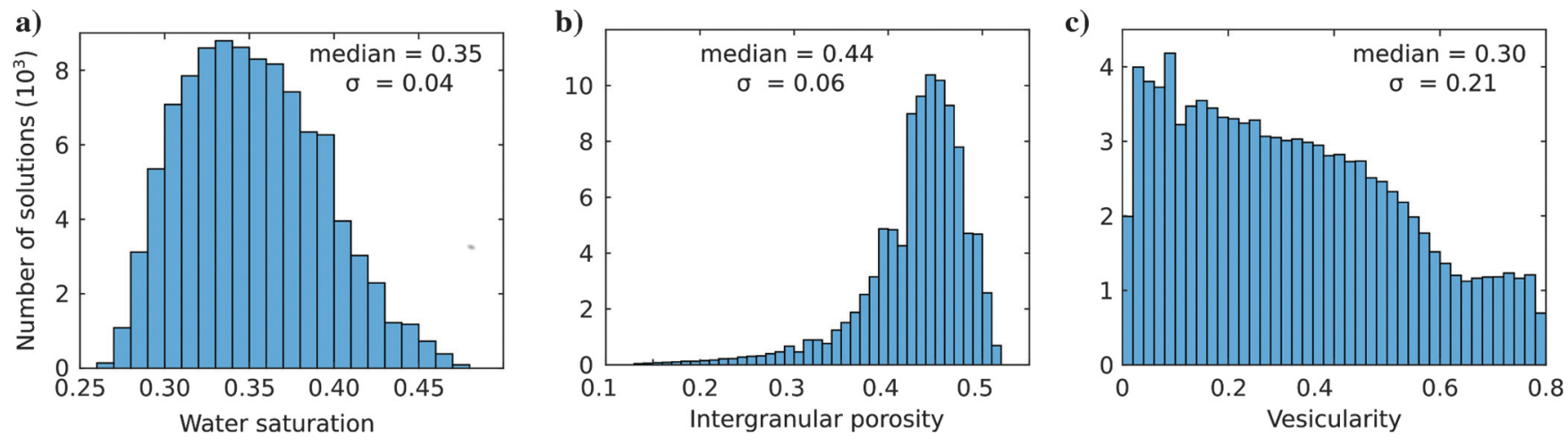

Figure 8. An example of accepted solutions from Monte Carlo petrophysical inversion for (a) $S_{w}$, (b) $\varphi_{g}$, and (c) $\varphi_{v}$ at a single spatial position. Relatively low standard deviations $(\sigma)$ of $S_{w}$, and $\varphi_{g}$ accepted solutions suggest well-constrained solutions, whereas the high standard deviation of accepted $\varphi_{v}$ solutions suggests poor sensitivity. 
The resolution and error of the velocity inversion results will propagate into a petrophysical inversion. Joint inversion of $V_{\mathrm{EM}}$, $V_{\mathrm{P}}$, and $V_{\mathrm{S}}$ would provide a more robust means to assess the impact of error and resolution propagation into petrophysical inversions by favoring solutions that are compatible with all the collocated data (e.g., a realistic Poisson's ratio). Cross-gradient joint-inversion techniques are recognized for their ability to improve the resolution of inversions from disparate data without prescribing a petrophysical relationship between inverted parameters (Gallardo and Meju, 2003). To our knowledge, cross-gradient joint-inversion techniques have yet to be developed for surface-located measurements of $V_{\mathrm{EM}}$, $V_{\mathrm{P}}$, and $V_{\mathrm{S}}$. Given our nonjoint velocity inversion of $V_{\mathrm{P}}$ and $V_{\mathrm{S}}$ detected anomalies of similar shape and magnitude, we assume that the resolution is suitable to test an inversion formulation of the dualporosity petrophysical model.

Similar to Bradford et al. (2015), we perform a Monte Carlo petrophysical inversion to estimate $S_{w}, \varphi_{g}$, and $\varphi_{v}$. For each position with $V_{\mathrm{EM}}, V_{\mathrm{P}}$, and $V_{\mathrm{S}}$ estimates, we probe the dual-porosity petrophysical model with 5,000,000 random realizations spanning plausible ranges of $S_{w}(0-0.75), \varphi_{g}(0-0.6)$, and $\varphi_{v}(0-0.8)$. We evaluate realizations with the objective function

$$
\begin{aligned}
\delta= & \left(w_{\mathrm{EM}}\left(V_{\mathrm{EM}}^{m}-V_{\mathrm{EM}}^{o}\right)\right)^{2}+\left(w_{\mathrm{P}}\left(V_{\mathrm{P}}^{m}-V_{\mathrm{P}}^{o}\right)\right)^{2} \\
& +\left(w_{\mathrm{S}}\left(V_{\mathrm{S}}^{m}-V_{\mathrm{S}}^{o}\right)\right)^{2},
\end{aligned}
$$

which measures the difference between the modeled $\left(V_{i}^{m}\right)$ and observed $\left(V_{i}^{o}\right)$ velocities. We regularize the inversion with weights
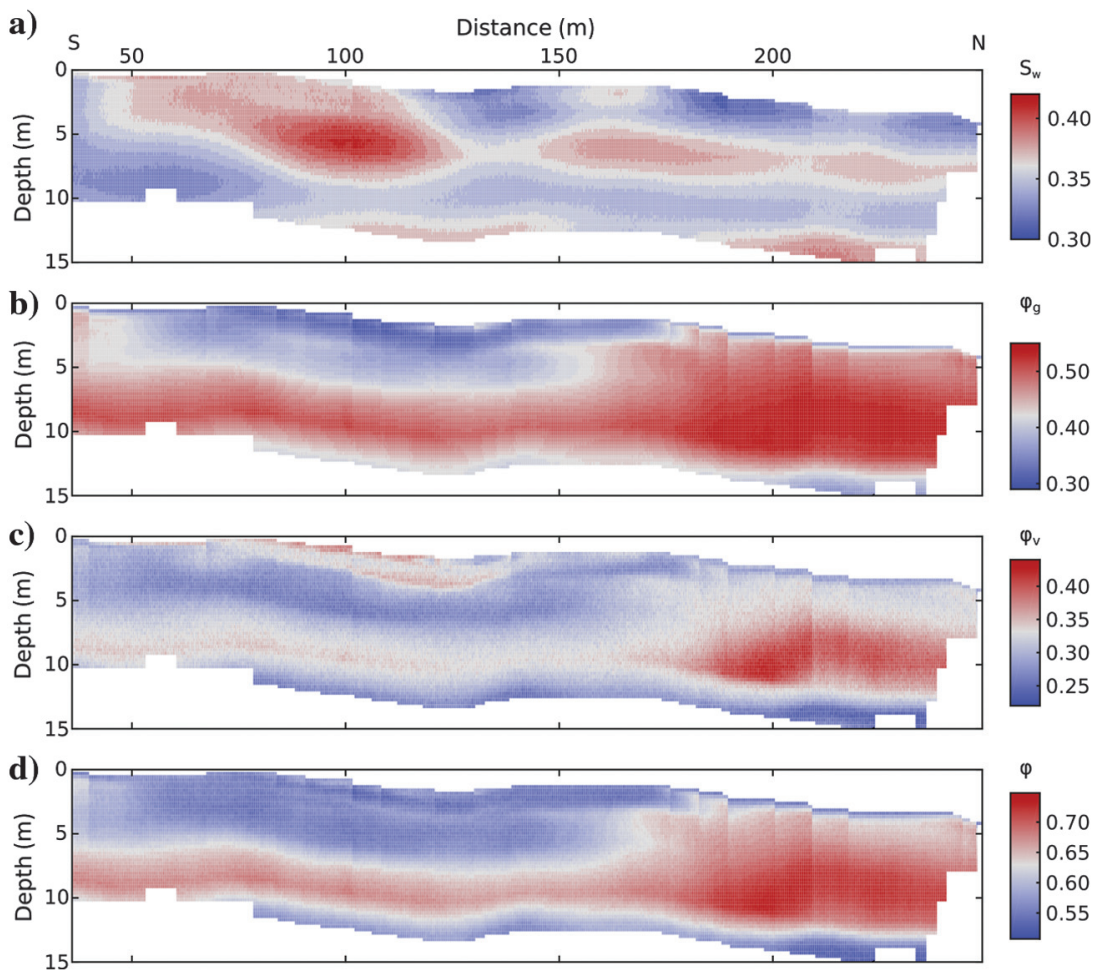

Figure 9. Petrophysical inversion results for (a) $S_{w}$, (b) $\varphi_{g}$, (c) $\varphi_{v}$, and (d) $\varphi$. Water saturation ranges between 0.30 and 0.42 and mirrors the morphology of the $V_{\mathrm{EM}}$ model. A low $\varphi$ anomaly in the upper $7 \mathrm{~m}$ corresponds to the location of the upper breccia in the outcrop (Figure 3c). Low $\varphi$ may contribute to the leftmost high $S_{w}$ anomaly. Poor sensitivity to $\varphi_{v}$ (Figure 8c) contributes to elevated $\varphi_{g}$ estimates and unrealistically low estimates of $\varphi_{v}$. $\left(w_{i}\right)$ that we determine by dividing the mean observed value of the velocity in question $\left(V_{i}\right)$ by the average observed $\mathrm{P}$-wave velocity (i.e., $V_{\mathrm{P}}=329 \mathrm{~m} \mathrm{~s}^{-1}$ ). Thus, $V_{\mathrm{P}}$ receives $w_{\mathrm{P}}=1$, and $w_{\mathrm{S}}$ and $w_{\mathrm{EM}}$ are scaled to the average magnitude of $V_{\mathrm{P}}$. We consider realzations within the minimum $2 \%$ misfit as valid solutions, and we cept the median value of valid solutions as the global solution

Water saturation solutions range between approximately 0.30 and 0.42 (Figure 9a), and they are morphologically similar to the $V_{\mathrm{EM}}$ model (Figure 7a). Intergranular porosity solutions are relatively ure $7 \mathrm{~b}$ and $7 \mathrm{c}$, and it suggests that poor sorting within the upper Vesicularity estimates are significantly lower than average for the 1981), and We expect that the reduced vesicularity within the breccias contributes to the elevated seismic velocity anomalies, as well. By combining $\varphi_{g}$ and $\varphi_{v}$ solutions with equation 1 , we obtain total $\varphi$ estimates ranging between 0.52 and 0.73 (Figure 9d).

The petrophysical inversion consistently estimates $S_{w}$ and $\varphi_{g}$ with relatively low standard deviations between 0.04-0.09 and $0.01-0.08$, respectively (Figure 8a and 8b). However, $\varphi_{v}$ solutions display much greater standard deviations (i.e., 0.18-0.24; Figure 8c), suggesting a lack of the sensitivity necessary to confidently estimate $\varphi_{v}$. Because seismic velocities are more sensitive to changes in intergranular porosity than $\varphi_{v}$ (Figure 2), the effects of unrealistic $\varphi_{v}$ solutions can be offset by minor shifts in $\varphi_{g}$ solutions. Thus, uncertainty in $\varphi_{v}$ propagates into estimates of total $\varphi$. In deposits in which changes in $\varphi_{v}$ are expected to be minor, such as pyroclastic deposits from a single eruption phase with few accidental clasts, it may reasonable to hold $\varphi_{v}$ to a constant measured value and directly estimate $\varphi_{g}$. Although $\varphi_{g}$ and $\varphi_{v}$ affect seismic velocities to separate extents (Figure 2), both forms of porosity are inversely proportional to seismic velocity. Therefore, petrophysical inversion of seismic and electromagnetic velocities is insufficient to estimate dual porosity.

\section{CONCLUSION}

We develop a petrophysical model of pyroclastic deposits to determine the effects of dual porosity and water content on electromagnetic and seismic velocities. Our petrophysical model reveals that seismic velocities are strongly affected by intergranular porosity and are moderately sensitive to vesicularity and water saturation.

In a GPR and active seismic case study in pyroclastic deposits at $\mathrm{MSH}$, we show that $V_{\mathrm{P}}$ and $V_{\mathrm{S}}$ tomography can image porosity anomalies caused by large breccias. However, joint petrophysical inversion of seismic and electromagnetic velocities 
is unsuccessful at separating the effects of intergranular porosity and vesicularity. Our results demonstrate that investigators must carefully consider the effects of unique lithology to estimate rock properties from geophysical measurements. Further efforts to determine geophysical parameters with independent responses to intergranular porosity and vesicularity would improve our ability to estimate porosity and water saturation in pyroclastic deposits.

\section{ACKNOWLEDGMENTS}

A National Science Foundation (grant no. NSF-EAR 0948588) and a Geological Society of America graduate student research grant funded this study. We are grateful to N. Pollock, T. Meehan, and T. Nielson who assisted with data acquisition. Many thanks go to G. Gribler and L. Liberty for their comments and assistance with MASW. We appreciate the reviews from S. Kruse, B. Heincke, and an anonymous reviewer.

\section{APPENDIX A}

\section{EQUATIONS FOR ELECTROMAGNETIC, COM- PRESSIONAL, AND SHEAR VELOCITIES}

\section{Electromagnetic velocity}

We use the CRIM equation (Wharton et al., 1980) to estimate the relative permittivity of pumice $\varepsilon_{p}$, by volumetrically mixing the relative permittivities of dacite $\left(\varepsilon_{d}=6.79\right)$ (Rust et al., 1999), water $\left(\varepsilon_{w}=80\right)$, and air $\left(\varepsilon_{a}=1\right)$, as

$$
\begin{aligned}
\varepsilon_{p}= & {\left[\sqrt{\varepsilon_{d}}+\left(\varphi_{v}-\varphi_{v} S_{w}\right)\left(\sqrt{\varepsilon_{a}}-\sqrt{\varepsilon_{d}}\right)\right.} \\
& \left.+\varphi_{v} S_{w}\left(\sqrt{\varepsilon_{w}}-\sqrt{\varepsilon_{d}}\right)\right]^{2} .
\end{aligned}
$$

The bulk relative permittivity follows as

$$
\begin{aligned}
\varepsilon= & {\left[\sqrt{\varepsilon_{p}}+\left(\varphi_{g}-\varphi_{g} S_{w}\right)\left(\sqrt{\varepsilon_{a}}-\sqrt{\varepsilon_{p}}\right)\right.} \\
& \left.+\varphi_{g} S_{w}\left(\sqrt{\varepsilon_{g}}-\sqrt{\varepsilon_{p}}\right)\right]^{2} .
\end{aligned}
$$

Finally, we model $V_{\text {EM }}$ with equation 2 .

\section{Seismic velocities}

To estimate seismic velocities, we first calculate the density $\rho$ by volumetrically mixing the average MSH dacite mineral composition $S_{w}, \varphi_{g}$, and $\varphi_{v}$. Then, we estimate the elastic moduli of nonporous dacite $\left(K_{\mathrm{ma}}, G_{\mathrm{ma}}\right)$ with the formula of Hill (1952) for crystalline aggregates. The bulk $\left(K_{d}\right)$ and shear moduli $\left(G_{d}\right)$ of dry pumice are calculated from $K_{\mathrm{ma}}$ and $G_{\mathrm{ma}}$ with the equations of Nur et al. (1998), with a critical porosity of 0.80 . We use Gassmann's equations (Gassmann, 1951; Biot, 1956) to calculate the bulk and shear moduli of pumice grains with pore water $\left(K_{P}\right.$ and $G_{P}$, respectively) as

$$
K_{P}=K_{d}+\frac{(1-b)^{2}}{\frac{1-\varphi_{v}-b}{K_{m a}}+\frac{\varphi_{v}}{K_{f}}},
$$

$$
G_{P}=G_{d}
$$

where $b=K_{d} / K_{m a}$. The bulk modulus of the pore fluid $\left(K_{f}\right)$ is the volumetric average of the bulk moduli of water and air, depending on $S_{w}$. We make several assumptions to use Gassmann's equations, including (1) frequency effects are negligible, (2) the pumice matrix is not altered by pore fluids, and (3) all pores are identical.

We use the following formulation of Bachrach et al. (2000), which applies to unconsolidated sediments, to include intergranular porosity in the elastic moduli of the sediment matrix. The effective bulk $\left(K_{\mathrm{HM}}\right)$ and shear moduli $\left(G_{\mathrm{HM}}\right)$ for a dry, randomly packed, unconsolidated matrix of identical, elastic spheres are

$$
K_{\mathrm{HM}}=\frac{n\left(1-\varphi_{g}\right)}{12 \pi r} \sigma_{n},
$$

$$
G_{\mathrm{HM}}=\frac{n\left(1-\varphi_{g}\right)}{20 \pi r}\left(\sigma_{n}+1.5 \sigma_{t}\right),
$$

as shown in Walton (1987), where $\sigma_{n}$ is the normal stiffness, $\sigma_{t}$ is the shear stiffness, $n$ is the average number of contacts per grain (assume $n=5$ ), and $r$ is the grain radius (assumed as $2 \mathrm{~mm}$ to model the fine lapilli). Mavko and Mukerji (1998) show that

$$
\begin{gathered}
\sigma_{n}=\frac{4 a G_{p}}{1-v}, \\
\sigma_{t}=\frac{8 a G_{P}}{2-v},
\end{gathered}
$$

where $v$ is the Poisson's ratio. The grain contact area $a$ relates to the confining force $F$, the contact curvature radius $R, v$, and $G_{P}$ :

$$
a=\left[\frac{3 F R(1-v)}{8 G_{P}}\right]^{1 / 3} .
$$

The radius of curvature is a function of the grain size, assuming the angularity of sand found in Bachrach et al. (2000),

$$
R=0.086 r
$$

Confining force relates to the grain properties, matrix properties, and the lithostatic pressure $P$,

$$
F=\frac{4 \pi r^{2} P}{n\left(1-\varphi_{g}\right)} .
$$

Lithostatic pressure is treated as

$$
P=\rho g D
$$

where $D$ is the depth and $g$ is the acceleration due to gravity (9.81 $\left.\mathrm{m} \mathrm{s}^{-2}\right)$.

As in Holbrook et al. (2014), we use the formulation of the modified upper and lower Hashin-Shtrikman bounds (Helgerud et al., 
$1999)$ to calculate the bulk and shear moduli of the dry frame $\left(K_{\mathrm{dry}}\right.$ and $\left.G_{\text {dry }}\right)$. Finally, we account for pore saturation to produce bulk elastic constants ( $K$ and $G$ ) as described by Santamarina et al. (2005), in which the bulk moduli of the fluid phase $\left(K_{\mathrm{fl}}\right)$, a fluid and particle suspension $\left(K_{\text {sus }}\right)$ and $K_{\text {dry }}$ are mixed as

$$
\begin{gathered}
K_{\mathrm{fl}}=\left(\frac{S_{w}}{K_{w}}+\frac{1-S_{w}}{K_{a}}\right)^{-1}, \\
K_{\mathrm{sus}}=\left(\frac{\varphi_{g}}{K_{\mathrm{fl}}}+\frac{1-\varphi_{g}}{K_{\mathrm{dry}}}\right)^{-1}, \\
K=K_{\mathrm{dry}}+K_{\mathrm{sus}},
\end{gathered}
$$

where $K_{a}$ and $K_{w}$ are the bulk moduli of the air and water, respectively. The shear modulus of the partially saturated matrix is unaffected:

$$
G=G_{\mathrm{dry}}
$$

Finally, we calculate $V_{\mathrm{P}}$ and $V_{\mathrm{S}}$ with equations 3 and 4.

\section{REFERENCES}

Bachrach, R., J. Dvorkin, and A. Nur, 2000, Seismic velocities and Poisson's ratio of shallow unconsolidated sands: Geophysics, 65, 559-564, doi: 10.1190/1.1444751.

Bais, G., P. Bruno, V. Di Fiore, and A. Rapolla, 2003, Characterization of shallow volcanoclastic deposits by turning ray seismic tomography: An application to the Naples urban area: Journal of Applied Geophysics, 52, 11-21, doi: 10.1016/S0926-9851(02)00230-6.

Barrash, W., and T. Clemo, 2002, Hierarchical geostatistics and multifacies systems: Boise Hydrogeophysical Research Site, Boise, Idaho: Water Resources Research, 38, 1196, doi: 10.1029/2002WR001436.

Bass, J. D., 1995, Elasticity of minerals, glasses, and melts, in T. J. Ahrens, ed., Mineral physics and crystallography: A handbook of physical constants: AGU, 2, 45-63.

Biot, M. A., 1956, Theory of propagation of elastic waves in a fluid saturated porous solid - Part I: Low frequency range: Journal of the Acoustical Society of America, 28, 168-178, doi: 10.1121/1.1908239.

Bosch, M., T. Mukerji, and E. F. Gonzalez, 2010, Seismic inversion for reservoir properties combining statistical rock physics and geostatistics: A review: Geophysics, 75, no. 5, A165-A176, doi: 10.1190/1 3478209 .

Bradford, J. H., 2006, Applying reflection tomography in the postmigration domain to multifold ground-penetrating radar data: Geophysics, 71, no. 1, K1-K8, doi: 10.1190/1.2159051.

Bradford, J. H., 2008, Measuring water content heterogeneity using multifold GPR with reflection tomography: Vadose Zone Journal, 7, 184-193, doi: 10.2136/vzj2006.0160.

Bradford, J. H., E. L. Babcock, H. P. Marshall, and D. F. Dickins, 2015, Targeted reflection-waveform inversion of experimental ground-penetrating radar data for quantification of oil spills under sea ice: Geophysics, 81, no. 1, WA59-WA70, doi: 10.1190/geo2015-0170.1.

Bradford, J. H., W. P. Clement, and W. Barrash, 2009, Estimating porosity with ground-penetrating radar reflection tomography: A controlled 3-D experiment at the Boise Hydrogeophysical Research Site: Water Resources Research, 45, W00D26, doi: 10.1029/2008WR006960.

Brand, B. D., C. Mackaman-Lofland, N. M. Pollock, S. Bendana, B. Dawson, and P. Wichgers, 2014, Dynamics of pyroclastic density currents: Conditions that promote substrate erosion and self-channelization Mount St. Helens, Washington (USA): Journal of Volcanology and Geothermal Research, 276, 189-214.

Fauria, K. E., M. Manga, and W. Zihan, 2017, Trapped bubbles keep pumice afloat and gas diffusion makes pumice sink: Earth and Planetary Science Letters, 460, 50-59, doi: 10.1016/j.epsl.2016.11.055.
Gallardo, L. A., and M. A. Meju, 2003, Characterization of heterogeneous near-surface materials by joint $2 \mathrm{D}$ inversion of $\mathrm{DC}$ resistivity and seismic data: Geophysical Research Letters, 30, 1658.

Gase, A. C., B. D. Brand, and J. H. Bradford, 2017, Evidence of erosional self-channelization of pyroclastic density currents revealed by groundpenetrating radar imaging at Mount St. Helens, Washington (USA): Geophysical Research Letters, 44, 2220-2228, doi: 10.1002/2016GL072178.

Gassmann, F., 1951, Elastic waves through a packing of spheres: Geophysics, 16, 673-685, doi: 10.1190/1.1437718.

Greaves, R. J., D. P. Lesmes, J. M. Lee, and M. N. Toksoz, 1996, Velocity variations and water content estimated from multi-offset, ground-penetrating radar: Geophysics, 61, 683-695, doi: 10.1190/1.1443996.

Gribler, G., L. M. Liberty, T. D. Mikesell, and P. Michaels, 2016, Isolating retrograde and prograde Rayleigh-wave modes using a polarity mute: Geophysics, 81, no. 5, V379-V385, doi: 10.1190/geo2015-0683.1.

Helgerud, M. B., J. Dvorkin, A. Nur, A. Sakai, and T. Collett, 1999, Elasticwave velocity in marine sediments with gas hydrates: Effective medium modeling: Geophysical Research Letters, 26, 2021-2024, doi: 10.1029/ 1999GL900421.

Hill, R., 1952, The elastic behavior of a crystalline aggregate: Proceedings of the Physical Society of London Series A, 65, 349-354.

Holbrook, W. S., C. S. Riebe, M. L. Elwaseif, J. Hayes, K. L. Basler-Reeder, D. Harry, A. Malazian, A. Dosseto, P. C. Hartsough, and J. W. Hopmans, 2014, Geophysical constraints on deep weathering and water storage potential in the Southern Sierra Critical Zone Observatory: Earth Surface Processes and Landforms, 39, 366-380, doi: 10.1002/esp.3502.

Huisman, J. A., S. S. Hubbard, J. D. Redman, and A. P. Annan, 2003, Measuring soil water content with ground penetrating radar: Vadose Zone Journal, 2, 476-491, doi: 10.2136/vzj2003.4760.

Klug, C., and K. V. Cashman, 1994, Vesiculation of May 18, 1980, Mount St. Helens magma: Geology, 22, 468-472, doi: 10.1130/0091-7613(1994) 022<0468:VOMMSH>2.3.CO;2.

Kuntz, M. A., P. D. Rowley, N. S. MacLeod, R. L. Reynolds, L. A. McBroome, A. M. Kaplan, and D. J. Lidke, 1981, Petrography and particle-size distribution of pyroclastic-flow, ash-cloud, and surge deposits, in P. O. Lipman and D. R. Mullineaux, ed., The 1980 Eruptions of Mount St. Helens, Washington: U. S. Geological Survey Professional Paper 1250, 525-539.

Manville, V., J. D. L. White, B. F. Houghton, and C. J. N. Wilson, 1998, The saturation behaviour of pumice and some sedimentological implications: Sedimentary Geology, 119, 5-16, doi: 10.1016/S0037-0738(98) 00057-8.

Mavko, G., and T. Mukerji, 1998, Bounds on low-frequency seismic velocities in partially saturated rocks: Geophysics, 63, 918-924, doi: 10.1190/1 1444402 .

Mavko, G., T. Mukerji, and J. Dvorkin, 2009, The rock physics handbook: Cambridge University Press.

Mindlin, R. D., 1949, Compliance of elastic bodies in contact: Journal of Applied Mechanics, 16, 259-268.

Nur, A., G. Mavko, J. Dvorkin, and D. Galmudi, 1998, Critical porosity: A key to relating physical properties to porosity in rocks: The Leading Edge, 17, 357-362, doi: 10.1190/1.1437977.

Pasquet, S., W. S. Holbrook, B. J. Carr, and K. W. W. Sims, 2016, Geophysical imaging of shallow degassing in a Yellowstone hydrothermal system: Geophysical Research Letters, 43, 12027-12035, doi: 10.1002/ 2016GL071306.

Rogers, J. J. W., and W. B. Head, 1961, Relationships between porosity, media size, and sorting coefficients of synthetic sands: Journal of Sedimentary Research, 31, 467-470.

Rust, A. C., and J. K. Russell, 2000, Detection of welding in pyroclastic flows with ground penetrating radar: Insights from field and forward modeling data: Journal of Volcanology and Geothermal Research, 95, 23-34.

Rust, A. C., and J. K. Russell, 2001, Mapping porosity variation in a welded pyroclastic deposit with signal and velocity patterns from groundpenetrating radar surveys: Bulletin of Volcanology, 62, 457-463.

Rust, A. C., J. K. Russell, and R. J. Knight, 1999, Dielectric constant as a predictor of porosity in dry volcanic rocks: Journal of Volcanology and Geothermal Research, 91, 79-96, doi: 10.1016/S0377-0273(99)00055-4. Santamarina, J. C., V. A. Rinaldi, D. Fratta, K. A. Klein, Y. H. Wang, G. H. Cho, and G. Cascante, 2005, A survey of elastic and electromagnetic properties of near-surface soils, in D. K. Butler, ed., Near-surface geophysics: SEG, 71-87.

Topp, G. C., J. L. Davis, and A. P. Annan, 1980, Electromagnetic determination of soil water content: Measurements in coaxial transmission lines: Water Resources Research, 16, 574-582, doi: 10.1029/ WR016i003p00574.

Van Dam, R. L., and W. Schlager, 2000, Identifying causes of groundpenetrating radar reflections using time-domain reflectometry and sedimentological analyses: Sedimentology, 47, 435-449, doi: 10.1046/j .1365-3091.2000.00304.x.

Walton, K., 1987, The effective elastic moduli of a random pack of spheres: Journal of the Mechanics and Physics of Solids, 35, 213-226. 
Wharton, R. P. G. A. Hazen, R. N. Rau, and D. L. Best, 1980, Electromagnetic propagation logging: Advances in technique and interpretation: Presented at the 55th Annual Fall Technical Conference and Exhibition, SPE, Paper 9267.

Whitham, A. G., and R. S. J. Sparks, 1986, Pumice: Bulletin of Volcanology, 48, 209-223.
Wohletz, K. H., and G. Heiken, 1992, Volcanology and geothermal energy: University of California Press.

Zimmer, M. A., M. Prasad, G. Mavko, and A. Nur, 2007, Seismic velocities of unconsolidated sands: Part 1 - Pressure trends from 0.1 to $20 \mathrm{MPa}$ : Geophysics, 72, no. 1, E1-E13, doi: 10.1190/1.2399459. 